\title{
Correction to: Population dynamics in canopy gaps: nonlinear response to variable light regimes by an understory plant
}

\author{
Sara E. Scanga
}

Published online: 21 August 2018

(C) Springer Nature B.V. 2018

Correction to: Plant Ecol (2014) 215:927-935, https://doi.org/10.1007/s11258-014-0344-9

The original Electronic Supplementary Material incorrectly categorized subpopulation $\mathrm{F}$ as a Control rather than a Gap. The corrected version is provided in this Correction, with subpopulation F correctly included as one of the 11 gaps.

Electronic supplementary material The online version of this article (https://doi.org/10.1007/s11258-018-0867-6) contains supplementary material, which is available to authorized users.

The original article can be found online at https://doi.org/10. 1007/s11258-014-0344-9.

S. E. Scanga $(\square)$

Department of Biology, Utica College, 1600 Burrstone

Road, Utica, NY 13502, USA

e-mail: sescanga@utica.edu 